\title{
Does Smoking Have a Significant Impact on Early Irritant Hand Dermatitis in Metal Workers?
}

\author{
B. Kütting ${ }^{a} \quad$ W. Uter ${ }^{b} \quad$ W. Weistenhöfer ${ }^{a} \quad$ T. Baumeister $^{\mathrm{a}} \quad$ H. Drexler ${ }^{\mathrm{a}}$ \\ ${ }^{a}$ Institute and Outpatient Clinic of Occupational, Social and Environmental Medicine, and bepartment of \\ Medical Informatics, Biometry and Epidemiology, Friedrich-Alexander University of Erlangen-Nuremberg, \\ Erlangen, Germany
}

\section{Key Words}

Occupational hand dermatitis · Smoking cessation

\begin{abstract}
Background: Although they know the long-term complications of smoking, many smokers require additional motivation for entering a smoking cessation programme. At the same time, smoking is considered a possible promoting factor for various skin diseases. Objective: The present study assesses the impact of smoking on occupational hand dermatitis in a high-risk population. Material and Methods: 1,355 metal workers, $97.3 \%$ of them shift workers, took part in a standardized interview and a dermatological examination of their hands. A subgroup of 1,020 males was willing to be followed-up for 1 year. Of those, $78.3 \%$ could be included in the final assessment. Results: Compared to the general German adult population the percentage of smokers was increased ( $41.7 \%$ at baseline). Probably due to self-selection bias and to a higher drop-out rate, the proportion of smokers was significantly lower at follow-up. Compared to nonsmokers, smokers had significantly higher score values for both erythematous lesions and vesicles. Conclusion: The present data might give additional support for occupational physicians or dermatologists to convince workers to quit smoking.
\end{abstract}

Copyright $\odot 2011$ S. Karger AG, Basel
(C) 2011 S. Karger AG, Basel

$1018-8665 / 11 / 2224-0375 \$ 38.00 / 0$

Fax +4161306 1234

E-Mail karger@karger.ch

www.karger.com
Accessible online at: www.karger.com/drm

\section{Introduction}

As severe chronic hand eczema (HE) causes considerable occupational, social and psychological disability [13], comprehensive primary prevention strategies at the workplace are needed. The economic and social impact of occupational HE is considerable for both the individual and society. In a substantial number of patients $\mathrm{HE}$ develops into a chronic condition even when the initial causative agent is avoided [4] and young professionals are often concerned [5]. In about 20\%, HE leads to sick leave longer than 7 days and in about $10 \%$ results in job change [6]. The reported annual incidence of work-related $\mathrm{HE}$ varies between 5 and 19 cases per 10,000 workers at occupational risk [7]. A high incidence rate has been associated with female sex, contact allergy, atopic dermatitis and wet work [6]. Employees in the metal working industry are at increased risk of hand dermatitis due to skin contact with metalworking fluids. Funke et al. [8] reported a 1-year cumulative incidence of $\mathrm{HE}$ of $9.2 \%$ (95\% CI $7.8-10.7 \%$ ) in a sample of 1,110 apprentices employed as metal workers in the automobile industry.

Previous research has demonstrated that job strain, increased work hours and shift work contribute to the risk of becoming a smoker or aggravating an existing smoking habit and may also present barriers to quit 
smoking [9]. In addition to its well-known long-term complications, smoking is also known to influence various inflammatory skin diseases. Thus, smoking has been shown to be a risk factor for developing lupus erythematodes [10-12], palmoplantar pustulosis [13-15] and, to some extent, also psoriasis $[16,17]$. Numerous studies have linked cigarette smoking with delayed wound healing and a number of wound-related complications [18]. Until now, contradictory findings have been reported concerning a possible association between tobacco smoking and HE [16, 19-26]. However, several studies showed an association between tobacco smoking and nickel sensitization [27-29]. The present study was aimed at determining the impact of smoking on the skin condition in a population at particular risk for developing occupational hand dermatitis (i.e. metal workers). As the majority of this group were shift workers and thus the proportion of smokers is expected to be even higher [30] than the reported $30 \%$ in the adult general population of Germany [31], a potential problem might thereby be aggravated.

\section{Material and Methods}

\section{Study Population}

At baseline, 1,355 metal workers from 19 mainly small or medium-sized factories in Germany were recruited. Except for a minority of $\mathrm{n}=36$ all included subjects were shift workers (rotating shifts: early morning, afternoon and night shifts). Only individuals able to work at the time of the investigation were included. None of our participants suffered from distinct hand eczema. All participants gave their informed consent to take part in a standardized interview and a dermatological examination of their hands. A subgroup of 1,020 male metal workers (406 smokers and 614 nonsmokers) which fulfilled our inclusion criteria for a recently published intervention study [32] gave their written informed consent to be followed-up for 1 year. The study design was approved by the local ethics committee of the University of Erlangen-Nuremberg. The study was performed from winter 2006/2007 to spring 2008 .

\section{The Interview}

The questionnaire used for a standardized personal interview has been described in detail elsewhere [33]. In short, the main part of the interview was related to working conditions, use of skin protection at the workplace and dermatological disorders of the hands. Questions related to dermatological disorders of the hands comprised the use of corticosteroids, dermatological consultations and disability due to hand dermatitis as surrogate for severe HE. Among other general questions, the participants were asked if they smoked or not. The interview was repeated after 12 months.

\section{Skin Examination}

In order to obtain objective - almost observer-independent [32] - results, the HEROS [34], a quantitative skin score, had been used. The score comprised all eruptions and physiologic abnormalities (e.g. dryness) characteristic of $\mathrm{HE}$ and made it possible to register the extent, intensity and anatomical site of each type of skin lesion as well.

\section{Statistical Methods}

Following descriptive analyses, differences in proportions between disjunct subgroups were tested for heterogeneity with the $\chi^{2}$ test, or Fisher's exact test in case of at least one expected cell frequency $<5$. Differences in metric variables were tested with the Wilcoxon test, in view of the often skewed distribution. Risk regarding dichotomous outcomes was quantified with an odds ratio (OR), accompanied by a $95 \%$ CI. In view of the exploratory nature of analyses, alpha adjustment techniques were not employed; significant results $(\mathrm{p}<0.05)$ are thus not regarded as confirmatory. For data management and analysis, SPSS (version 17.0) and SAS (version 9.2, SAS Institute, Cary, N.C., USA) software packages were used.

\section{Results}

At baseline, the majority of participants were male $(96.7 \% ; \mathrm{n}=1,310)$, aged from 17 to 64 years (median 42 years; mean 40.8 years), whereas only 45 participants were females. The female workers were between 17 and 59 years old (median: 36 years; mean: 37.6 years). The proportion of self-reported smokers was $41.6 \%$ in male participants and $42.2 \%$ in females. Only 2 subjects did not answer the question concerning their current smoking status. We subdivided the male participants into three age groups (ranges according to the 'German Health Update' (2008/9) [35]). Group I from 18 to $<30$ years comprised 199 participants (15.2\%), group II from 30 to $<45$ years 599 participants (45.8\%) and group III 509 (38.9\%), respectively. The proportions of smokers were 53.8, 43.4 and $34.8 \%$, respectively.

Significantly more smokers reported to suffer or to have suffered from dyshidrotic vesicles than nonsmokers ( 25.5 vs. $19.3 \% ; p=0.007, \chi^{2}$ test). Based on self-reports of the medical history, no significant differences between smokers and nonsmokers could be observed for atopic dermatitis, former or present HE, topical application of steroids on the hands, dermatological consultations and disability due to HE. Using the total skin score as a quantitative and objective parameter, there was no significant difference between smokers and nonsmokers (for further details, see table 1). However, there was a weak but significant difference for erythema as a surrogate for acute inflammation, as smokers had significantly higher score values for erythematic skin lesions on both hands than nonsmokers ( $\mathrm{p}=0.016$; Wilcoxon test, fig. 1). 
Table 1. Comparison of smokers and nonsmokers at baseline examination

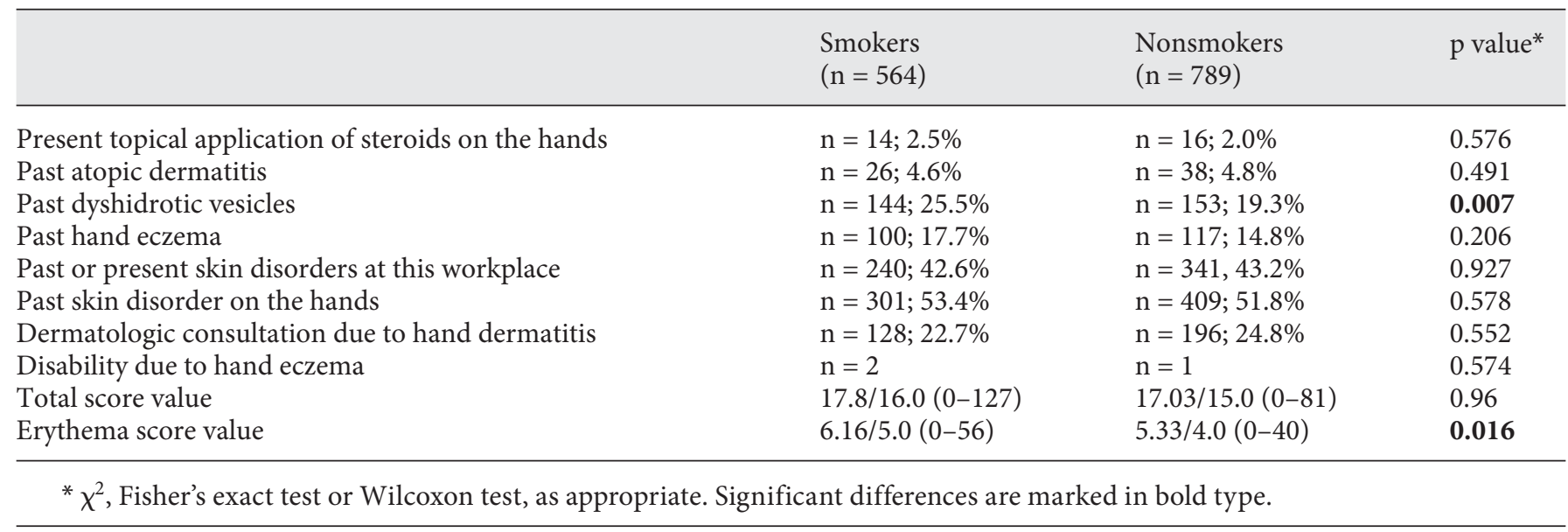

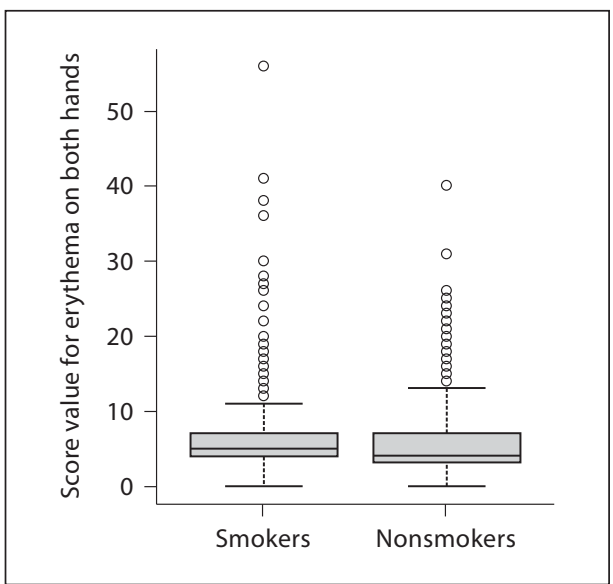

Fig. 1. Smokers have significantly more erythema on the hands than nonsmokers $(\mathrm{p}=0.016)$.

Of the 1,020 male metal workers, 800 (78.4\%) could be followed up for 1 year. Smoking at baseline significantly increased the risk of being lost to follow-up (OR 1.49, 95\% CI 1.19-1.85). The prevalence of smokers in the subsample was at $37.8 \%$ and thus still higher than in the German general population. After 1 year of follow-up, it decreased to $34.4 \%$ since significantly more participants stopped smoking than took it up ( $\mathrm{p}=0.0012$, McNemar test). Those smokers present at follow-up reported slightly more frequently to use topical steroids on their hands at present ( 2.9 vs. $1 \%, \mathrm{p}=0.038$ ) or having used steroids in the past 6 months ( 4.4 vs. $2.1 \%, \mathrm{p}=0.068$ ). Smokers also reported episodes of dyshidrotic HE in the follow-up period more frequently $(p=0.027)$. Furthermore smokers reported more often on episodes of hand dermatitis, on dermatological consultations and disability due to hand dermatitis. Most other differences between smokers and nonsmokers were only slight and failed statistical significance. Based on the HEROS results, significant differences between smokers and nonsmokers were observed only for erythema and vesicles (table 2). These results were not influenced by the intervention of the aforementioned study [32], and there was no association between smoking status and intervention effect. At the 1-year follow-up, only 3 subjects, 2 of them smokers, reported that they had been unable to work in the past year and a total of 13 subjects reported current topical application of steroids on both hands. In this small subgroup, the proportion of smokers was with $2.9 \%$ slightly higher than those of nonsmokers (1\%).

\section{Discussion}

Despite knowing the long-term sequelae of smoking, many smokers find it hard to quit this habit and require additional motivation. Occupational physicians can play an active role in smoking prevention and cessation and must provide their smoking employees incentive, guidance and intervention to help them discontinue this habit. Tobacco smoking is known to influence various inflammatory skin diseases [10-26]. An association between smoking and HE has been postulated [16, 19, 22-26] and the present findings underscore that smoking has a negative impact on work-related HE. This might provide the occupational physician with yet another good reason 
Table 2. Comparison between smokers and nonsmokers at 1-year follow-up; morphologic pattern refers to both hands (palms and backs)

\begin{tabular}{lll}
\hline & $\begin{array}{l}\text { Smokers } \\
(\mathrm{n}=275)\end{array}$ & $\begin{array}{l}\text { Nonsmokers } \\
(\mathrm{n}=525)\end{array}$ \\
\hline Present topical application of steroids on the hands & $\mathrm{n}=8 ; 2.9 \%$ & $\mathrm{n}=5 ; 1.0 \%$ \\
Topical application of steroids in the past 6 months & $\mathrm{n}=12 ; 4.4 \%$ & $\mathrm{n}=11 ; 2.1 \%$ \\
Past dyshidrotic vesicles in the last six months & $\mathrm{n}=26 ; 9.5 \%$ & $\mathrm{n}=28 ; 5.3 \%$ \\
Past hand eczema & $\mathrm{n}=18 ; 6.5 \%$ & $\mathrm{n}=19 ; 3.6 \%$ \\
Past or present skin disorders at this workplace & $\mathrm{n}=57 ; 20.7 \%$ & $\mathrm{n}=104 ; 19.8 \%$ \\
Dermatologic consultation due to hand dermatitis & $\mathrm{n}=9 ; 3.3 \%$ & $\mathrm{n}=15 ; 2.9 \%$ \\
Disability due to hand eczema & $\mathrm{n}=2 ; 0.7 \%$ & $\mathrm{n}=1 ; 0.2 \%$ \\
Total score value mean/median (range) & $16.97 / 16.0(0-61)$ & $16.04 / 15.0(0-65)$ \\
Erythema mean/median (range) & $6.17 / 5.0(0-26)$ & $5.5 / 5.0(0-52)$ \\
Papules mean/median (range) & $0 / 0(0-0)$ & $0.05 / 0(0-1)$ \\
Vesicles mean/median (range) & $0.14 / 0(0-9)$ & $0.0229 / 0(0-3)$ \\
Erosion mean/median (range) & $0.0545 / 0(0-3)$ & $0.0571 / 0(0-2)$ \\
Scabs mean/median (range) & $1.26 / 0(0-27)$ & 0.758 \\
Fissures mean/median (range) & $0.15 / 0(0-5)$ & 0.743 \\
Excoriation mean/median (range) & $1.5 / 1(0-12)$ & 0.273 \\
\hline
\end{tabular}

${ }^{*} \chi^{2}$, Fisher's exact test or Wilcoxon test, as appropriate. Significant differences are marked in bold type.

to encourage smoking cessation. On the other hand, it indicates that smoking behavior might also have a relevant impact in the field of occupational dermatology. Recent data from the Robert Koch Institute's telephone survey entitled 'German Health Update' [35] performed from July 2008 to April 2009 on 25,000 adults revealed that the proportion of male smokers in the age group of 18 to $<30$ years was $43.2 \%$, in the age group of 30 to $<45$ years $42.5 \%$, and in the group of 45 to $<65$ years was $34.6 \%$.

Compared to these data, in our sample at baseline the proportion of male smokers in the age group of 30 years to $<45$ years was marginally higher ( 43.4 vs. $42.5 \%)$ and also quite equal in the oldest age class (34.8 vs. $34.6 \%$ ). The most striking difference was observed in the youngest age group (53.8 vs. $43.2 \%$ ). In all recruited individuals the total percentage of smokers was $41.7 \%$; in the sample that was willing to be followed up $(n=1,020)$, the percentage of smokers at baseline was 37.8 and $34.4 \%$ $(\mathrm{n}=800)$ at the follow-up examination after 1 year, respectively.

This smoking prevalence can be attributed to the fact that most individuals in our sample were shift workers. In general, night workers smoke more and have significantly higher BMI, serum total cholesterol, and triglycerides than day workers [30]. Shift work is suggested to promote unhealthy behavior, since disturbances of sleep and circadian rhythms and stress on family and social life might result in physiological changes and maladaptive coping strategies [36]. Until now, inconsistent or even contradictory findings concerning the potential influence of smoking on worsening HE have been reported in occupational settings [21-24] as well as in populationbased surveys $[16,25,26]$.

\section{Results of Studies in Occupational Settings}

The study of Sprince et al. [21] researched differences in the occurrence of contact dermatitis between machine operators exposed to metal-working fluids $(\mathrm{n}=158)$ and unexposed assemblers $(n=51)$ and found weak evidence that smoking might be associated with occupational HE, especially dyshidrotic $\mathrm{HE}$, in metal workers. In contrast, Berndt et al. [22] did not find a positive correlation between the extent of cigarette smoking and the development of HE in their cohort of 201 metalworker trainees. Montnémery et al. [23] assessed the prevalence of selfreported HE in an adult Swedish population and its relationship to age, gender, smoking habits and occupation in a cross-sectional questionnaire study. Using multiple logistic regression analysis both female sex $(\mathrm{OR}=1.91$; 95\% CI 1.47-2.47) and smoking (OR $=1.35,95 \% \mathrm{CI}$ 0.1.04-1.75) were found to be independent risk factors for HE (1-year prevalence). Aggregated risk occupation or categorized occupation such as medical or nursing work, production or service was, however, not significantly as- 
sociated with 1-year prevalence of HE. Based on self-reports obtained from 13,452 individuals, Meding et al. [24] recently found no clear association between 1-year prevalence of $\mathrm{HE}$ and smoking. Herein retrospective data of three occupational cohorts (e.g. bakers, dental technicians and hairdressers) and their controls were included. The controls were randomly selected individuals from the general population with a similar age and sex distribution. Only heavy smoking, i.e. more than 10 cigarettes per day, slightly increased the risk of HE.

\section{Results of Population-Based Surveys}

In a population-based study performed on 25,851 volunteers in Sweden Meding et al. [25] recently detected a dose-response relation between the level of smoking and 1 -year prevalence of HE (prevalence ratio 1.05; $\mathrm{p}<0.001$ ), indicating a very slightly (by $5 \%$ ), but significantly increased prevalence of $\mathrm{HE}$ among individuals with higher consumption of tobacco. Thyssen et al. [26] confirmed that tobacco smoking was positively associated with HE by analyzing data of a cross-sectional study on 3,471 volunteers of the general population of Copenhagen. In contrast to Meding et al. [24, 25], Thyssen et al. [26] stated that current light smokers ( $<15$ g daily) had a higher prevalence of HE than current heavy smokers. However, another huge population-based survey among 18,747 Norwegian urban adults [16] completely failed to find an association between cigarette smoking and HE.

So even though several studies identified smoking as a possible factor promoting HE [21, 23-26], a consistent dose-dependent relationship has not been established yet [24-26]. This may be due to the fact that in these studies smokers tended to palliate their habit and thus their specifications concerning the amount of their smoking might be unreliable, although in studies that correlated hemoglobin adducts of acrylonitrile with self-reported daily amount of cigarettes the correlation was excellent [37]. In order to answer the question of dose-dependency objectively, further studies, combining objective skin examination with hemoglobin adducts of acrylonitrile, are needed. In this study, questions concerning the smoking status of the participants therefore omitted aspects of quantity and were restricted to a qualitative Yes/No question.

Concerning the skin status, however, in contrast to the aforementioned population-based studies, the present study was not solely based on self-reports on HE but also on a detailed quantitative skin examination of both hands. Therefore, a clear, objective distinction between acute, subacute or chronic HE was possible by assessing the predominance of either primary or secondary erup-

Impact of Smoking on Occupational Hand Dermatitis tions. Furthermore, the study population was quite homogenous and thus the results had not to be adjusted for social or biological confounders.

In the present study, smokers had significantly higher score values for both erythematous lesions and vesicles, indicating an acute stage of $\mathrm{HE}$, based on results obtained by use of the HEROS. This observation is in line with previous reports on the predominance of vesicular eczema among smokers in smaller samples $[19,21]$ and it can be interpreted as a further negative health impact of both smoking and shift work.

One can speculate that our sample which could be followed up for 1 year was more health-conscious compared to the total of included subjects at baseline, since it was willing to be followed up in the first place. This assumption is supported further by the lower percentage of smokers at follow-up, implying a higher drop-out rate of smokers that caused a self-selection bias or smoking cessation. But even without the drop-outs, the skin status of the remaining smokers strongly suggested that smoking took its toll on their skin condition.

Occupational physicians have a preventive assignment. In order to preserve and possibly promote the health of their patients, they need to take into consideration all possible negative agents. The negative effects of smoking on the skin condition has to be observed under two seemingly diametrical aspects since occupational skin diseases comprise a large part of all occupational diseases. Occupational physicians and occupational dermatologists as skin experts must be familiar with all possible influences detrimental to the skin. This is crucial in order to determine if worsening of a skin condition is caused by occupational influences alone or if it is possibly aggravated by inflammatory effects of life-style factors (e.g. smoking).

Smoking is a major health risk and the preventative assignment of the occupational physician therefore comprises smoking prevention. Constant motivation of employees to quit and continually abstain is at the same time the most important and the most difficult task in this enterprise. On the other hand, the prevention of skin diseases is, again, under the major aims of occupational prevention. As active participants in both the prevention/ cessation of smoking and prevention of skin diseases, the present data might give the occupational physician additional support for counseling workers at increased risk of developing $\mathrm{HE}$ to quit smoking. Our results provide a further strategic opportunity to motivate smoking cessation at the workplace and reduce smoking-related morbidity and even mortality. 


\section{Acknowledgements}

The study was funded by the German Statutory Accident Insurance (DGUV) and the Franz-Koelsch-Stiftung e.V. We thank all persons involved for their efforts in making the study possible. Additionally, we thank all volunteers for participation in this study.

\section{Disclosure Statement}

All authors declare that they have no conflict of interest relevant to the study.

\section{References}

1 Cvetkovski RS, Rothman KJ, Olsen J, Mathiesen B, Iversen L, Johansen JD, Agner T: Relation between diagnosis on severity, sick leave and loss of job among patients with occupational hand eczema. Br J Dermatol 2005; 152:93-98.

2 Cvetkovski RS, Zachariae R, Jensen $\mathrm{H}$, Olsen J, Johansen JD, Agner T: Quality of life and depression in a population of occupational hand eczema patients. Contact Dermatitis 2006;54:106-111.

3 Moberg C, Alderling M, Meding B: Hand eczema and quality of life: a population-based study. Br J Dermatol 2009;161:397-403.

4 Diepgen TL, Agner T, Aberer W, Berth-Jones J, Cambazard F, Elsner P, McFadden J, Coenraads PJ: Management of chronic hand eczema. Contact Dermatitis 2007;57:203-210.

5 Diepgen TL: Occupational skin-disease data in Europe. Int Arch Occup Environ Health 2003;76:331-338.

6 Thyssen JP, Johanssen JD, Linneberg A, Menné $\mathrm{T}$ : The epidemiology of hand eczema in the general population - prevalence and main findings. Contact Dermatitis 2010;62:75-87.

7 Belsito DV: Occupational contact dermatitis: etiology, prevalence, and resultant impairment/disability. J Am Acad Dermatol 2005; 53:303-313.

8 Funke U, Fartasch M, Diepgen TL: Incidence of work-related hand eczema during apprenticeship: first results of a prospective cohort study in the car industry. Contact Dermatitis 2001;44:166-172.

9 Sorensen G, Quintiliani L, Pereira L, Yang $M$, Stoddard A: Work experiences and tobacco use: findings from the gear up for health study. J Occup Environ Med 2009;51:87-94.

10 Gallego H, Crutchfield CE 3rd, Lewis EJ, Gallego HJ: Report of an association between discoid lupus erythematodes and smoking. Cutis 1999;63:231-234.

11 Miot HA, Bartoli Miot LD, Haddad GR: Association between discoid lupus erythematosus and cigarette smoking. Dermatology 2005;211:118-122.

12 Koskemnics S, Järvinen TM, Onkamo P, Panelius J, Tuovinen U, Hasan T, Ranki A, Saarialho-Kere U: Clinical and laboratory characteristics of Finnish lupus erythematosus patients with cutaneous manifestations. Lupus 2008;17:337-347.

13 O'Doherty CJ, MacIntyre C: Palmoplantar pustulosis and smoking. Br Med J 1985;291: 861-864.
14 Hagforsen E, Awder M, Lefvert AK, Nordlind K, Michaëlsson G: Palmoplantar pustulosis: an autoimmune disease precipitating smoking? Acta Derm Venereol 2002;82:341346.

15 Michaëlsson G, Gustafsson K, Hagforsen E: The psoriasis variant palmoplantar pustulosis can be improved after cessation of smoking. J Am Acad Dermatol 2006;54:737-738.

16 Bø K, Thoresen M, Dalgard F: Smokers report more psoriasis, but not atopic dermatitis or hand eczema: results from a Norwegian Population survey among adults. Dermatology 2008;216:40-45.

17 Attwa E, Swelam E: Relationship between smoking-induced oxidative stress and the clinical severity of psoriasis. J Eur Acad Dermatol Venereol 2011;25:782-787.

18 Metelitsa AI, Lauzon GJ: Tobacco and the skin. Clin Dermatol 2010;28:384-390.

19 Edman B: Palmar eczema: a pathogenetic role for acetylsalicylic acid, contraceptives and smoking. Acta Derm Venereol 1988;68: 402-407.

20 Uter W, Gefeller O, Schwanitz J: Occupational dermatitis in hairdressing apprentices: early-onset irritant skin damage. Curr Probl Dermatol 1995;23:49-55.

21 Sprince NL, Palmer JA, Popendorf W, Thorne PS, Selim MI, Zwerling C, Miller ER: Dermatitis among automobile production machine operators exposed to metal-working fluids. Am J Ind Med 1996;30:421-429.

22 Berndt U, Hinnen U, Iliev D, Elsner P: Hand eczema in metalworker trainees - an analysis of risk factors. Contact Dermatitis 2000; 43:327-332.

23 Montnémery P, Nihlén U, Löfdahl CG, Nyberg P, Svensson A: Prevalence of hand eczema in an adult Swedish population and the relationship to risk occupation and smoking. Acta Derm Venereol 2005;85:429-432.

24 Meding B, Alderling M, Albin M, Brisman J, Wrangsjö K: Does tobacco smoking influence the occurrence of Hand eczema. $\mathrm{Br} \mathrm{J}$ Dermatol 2009; 160:514-518.

25 Meding B, Alderling M, Wrangsjö K: Tobacco smoking and hand eczema: a populationbased study. Br J Dermatol 2010;163:752-756.

26 Thyssen JP, Linneberg A, Menné T, Nielsen $\mathrm{NH}$, Johansen JD: The effect of tobacco smoking and alcohol consumption on the prevalence of self-reported hand eczema: a cross-sectional population-based study. $\mathrm{Br}$ Dermatol 2010;162:619-626.
27 Thyssen JP, Johansen JD, Menné T, Nielsen $\mathrm{NH}$, Linneberg A: Effect of tobacco smoking and alcohol consumption on the prevalence of nickel sensitization and contact sensitization. Acta Derm Venereol 2010;90:27-33.

28 Dotterud LK, Smith-Sivertsen T: Allergic contact sensitization in the general adult population: a population-based study from Northern Norway. Contact Dermatitis 2007; 56:10-15.

29 Linneberg A, Nielsen NH, Menné T, Madsen $\mathrm{F}$, Jørgensen T: Smoking might be a risk factor for contact allergy. J Allergy Clin Immunol 2003;111:980-984.

30 Biggi N, Consonni D, Galluzzo V, Sogliani M, Costa G: Metabolic syndrome in permanent night workers. Chronobiol Int 2008;25: 443-454.

31 Böning J: Risk behaviour in association with addictive drugs - data and insights on treatment (in German). Gesundheitswesen 2004; 66:S71-S79.

32 Kütting B, Baumeister T, Weistenhöfer W, Pfahlberg A, Uter W, Drexler H: Effectiveness of skin protection means in prevention of occupational hand eczema: results of a prospective randomized controlled trial over a follow-up period of one year. $\mathrm{Br} J \mathrm{Der}-$ matol 2010;162:362-370.

33 Kütting B, Weistenhöfer W, Baumeister T, Uter W, Drexler H: Current acceptance and implementation of preventive strategies for occupational hand eczema in 1355 metal workers in Germany. Br J Dermatol 2009; 161:390-396.

34 Weistenhöfer W, Baumeister T, Drexler H, Kütting B: How to quantify skin impairment in primary and secondary prevention? HEROS: a proposal of a hand eczema score for occupational screenings. Br J Dermatol 2011; 164:807-813.

35 German Federal Reporting: http://www.rki. $\mathrm{de} / \mathrm{nn} \_217400 / \mathrm{EN} /$ Content/Health__Reporting/health__reporting__node.html? nnn=true.

36 Bushnell PT, Colombi A, Caruso CC, SangWoo TAK: Work schedules and health behaviour outcomes at a large manufacturer. Industrial Health 2010;48:395-405.

37 Kütting B, Uter W, Drexler H: The association between self-reported acrylamide intake and haemoglobin adducts as biomarkers of exposure. Cancer Causes Control 2008;19:273-281. 